\title{
THE REDISCOVERY OF \\ CAMPONOTUS (MYRMAPHAENUS) YOGI WHEELER (HYMENOPTERA: FORMICIDAE)
}

\author{
By Wm. S. Creighton, City Collegge, New York ${ }^{11}$ \\ and Roy R. Snelling, Los Angeles County Museum²
}

No North American ant has been more of an enigma than Wheeler's Camponotus yogi. Much of this is due to the fact that the two types of yogi were misplaced when a part of the Wheeler Collection was transferred from the Museum of Comparative Zoölogy to the American Museum of Natural History in 1938. For the next twenty-six years Wheeler's description of yogi was the only source of information on this species (I). Of necessity this description was the basis for the treatment of yogi in The Ants of North America (2). Unfortunately, one of the key features chosen (the length of the antennal scape) was incorrectly described by Wheeler; hence the key for yogi in the above publication is confusing rather than helpful. It appears that yogi has been saved from even greater confusion only because so little additional material has been taken. In 1958 F. Raney found a few specimens at the Oak Creek Ranger Station in San Diego County, California. In 1963 the junior author took three colonies of yogi at Etiwanda, in San Bernardino County, California. The senior author at first refused to believe that this material could be yogi because it so obviously failed to agree with Wheeler's description. Then, in 1964, the two types of yogi were discovered in the collection of the American Museum of Natural History. These established the fact that the Oak Creek and Etiwanda specimens are yogi.

Several of the shortcomings of Wheeler's description can be attributed to his attempt to relate yogi to the subgenus Colobopsis. Whether he realized it or not, Wheeler described important features of the head of the major of yogi from a position where it most closely resembled that of a Colobopsis major. That is to say, the head was not viewed in full face but tilted forward until the truncated anterior portion and the mandibles were barely visible. There is no possible doubt about this for the "broadly excised posterior border" which Wheeler described for the head of the yogi major

\footnotetext{
${ }^{1}$ Emeritus Professor, Department of Biology

${ }^{2}$ Senior Preparator, Department of Entomology

Published with a Grant-in-Aid of Research from the Society of the Sigma Xi. Manuscript received by the editor May 9, 1966
} 
cannot be seen unless the head is tilted forward. In conventional full face view the occipital border of the major of yogi is flat or very slightly convex (See Plate I2, Fig. 2). Precisely the same explanation applies to Wheeler's statement that the scapes of the major of yogi "reach the posterior corners of the head". When the head of the major is tilted far enough forward to show the excavated rear border of the occiput, it is true that the scapes appear to reach the occipital corners. But in conventional full face view they extend beyond the occipital corners. It is obvious that tilting the head would not greatly affect the configuration of the frontal carinae and, if one is willing to unravel the description that both Wheeler and Forel customarily applied to lyrate carinae, then these were accurately described. In the writer's opinion this is the only feature in the description of yogi which enabled Emery to allocate the species to the subgenus Myrmaphaenus for, with strongly lyrate frontal carinae, it cannot belong to Colobopsis.

Finally, there is the matter of pilosity. Wheeler recognized that some of the cephalic pilosity of the major of $y o g i$ is notably different from that on other parts of the body. He gave an accurate description of the short, blunt, reclinate hairs that arise from the foveolae of the clypeus and the adjacent parts of the genae. But he failed to mention the erect hairs which occur on the sides of the head from the rear border of the eye to the mandibular insertion. These hairs also occur on the lateral parts of the gula and over an area extending inward toward the antennal fossa. Although short, they are quite numerous and form a conspicuous fringe on the anterior half of the head. Their structure is unusual for, although each hair is of uniform thickness throughout most of its length, many of them have enlarged tips. The enlarged tip is often spherical and such hairs look remarkably like the upper ends of insect pins.

One of the most characteristic features of yogi is the sculpture on the front of the head of the major. The surface is rough and covered with coarse elevations and depressions which are too broad and illdefined to be called rugae. The roughened areas on the clypeus have no fixed direction but those on the genae approximately parallel the long axis of the head. Among these roughened ridges are scattered oval foveolae from which flattened hairs arise, but these are difficult to see because the entire roughened surface is evenly covered with very fine, densely set, oval punctures which give the area a

Explanation of Plate 12

Camponotus (Myrmaphaenus) yogi Wheeler. Figure 1. Head of female. Figure 2. Head of major. Both figures drawn to the same scale. 

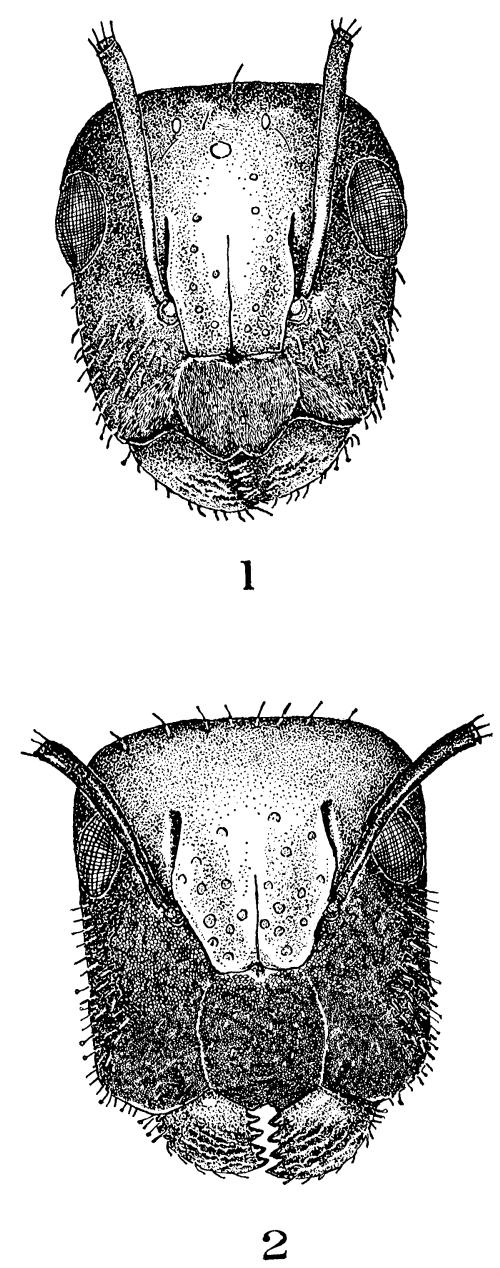

Creighton and Snelling - Camponotus 
granular appearance. The sculpture just described is confined to the anterior half of the head. The frontal lobes are heavily shagreened, the middle of the occiput more feebly shagreened and the sides of the head and the occipital angles are smooth and shining. There are conspicuous circular punctures on the frontal lobes, smaller oval ones on the sides of the head and very small and obscure punctures on the occiput. No other North American species of Camponotus has a comparable cephalic sculpture and yogi may be recognized by this feature alone.

There is nothing in Wheeler's treatment of yogi more exasperating than his statement that this species is related to Colobopsis. In 1896 Emery listed the distinguishing features of Colobopsis (3). When Wheeler monographed our North American forms in 1904 he repeated Emery's criteria and added two of his own (4). According to Wheeler's summary the female and major worker of Colobopsis have a head in which the truncated portion is circular in outline and sharply separated from the remainder of the head (marginate). There are conspicuous, umbilicate punctures on the sides of the head immediately behind the truncation. The mandibles have an external ridge or angle which separates the anterior face from the equally large latero-ventral face. Medias are rare or lacking and the pupae are not enclosed in cocoons. Because of the limited type material of yogi Wheeler could not know that in this species medias are present and the larvae are enclosed in cocoons. Nor could he know anything about the structure of the female. Nevertheless, Wheeler was aware that the truncated portion of the head of the major of yogi is neither circular in outline nor marginate. He was aware that there is no external ridge on the major's mandible. Since he described the dense, granular, sculpture which obscures the foveolae on the sides of the head of the major of yogi, Wheeler must have realized that these foveolae are scarcely comparable to the distinct, umbilicate, punctures of the Colobopsis major. In short, not a single feature of the major of yogi agreed with the major of Colobopsis as that caste was defined by Wheeler in 1904 .

These contradictions are annoying but they are not inexplicable. Wheeler's initial views on Colobopsis were based almost entirely on species in the truncatus-impressus complex, as were the views which Emery had expressed earlier. By 1907, due to the many identified exotics which he had received from Forel, Wheeler was prepared to expand his original views on Colobopsis. It is regrettable that when he described yogi Wheeler failed to make it clear that some of the Asiatic and South Pacific species assigned to Colobopsis are more 
aberrant than $y$ ogi when compared to species in the truncatus-imressus complex. With this in mind the question is not whether Wheeler was justified in placing yogi in Colobopsis but whether Emery was any better off when he transferred it to Myrmaphaenus. At present no final answer can be given for both subgenera are unusually heterogeneous. Nevertheless we prefer Emery's treatment for the following reasons:

( I ) It is quite impossible to relate yogi to the truncatus-impressus complex in Colobopsis.

(2) If yogi is assigned to Colobopsis it will have to be placed in one of the Old World groups which are, at present, too ill-defined to permit certainty of assignment.

(3) There is no feature of yogi which would prevent its inclusion in Myrmaphaenus and it possesses several features which indicate that it fits better in that subgenus than in Colobopsis.

Most of these features have been mentioned above but one of them merits a more detailed discussion. The head of the female of yogi resembles that of the media rather than that of the major. In full face view the head of the major is as wide (in some specimens slightly wider) at the level of the rear of the clypeus as it is at the anterior border of the eyes. 'This gives the head a distinctly rectangular outline, for the sides turn in toward the mandibular insertions abruptly below the level of the middle of the clypeus. In the female and media the sides of the head converge gradually from the level of the anterior border of the eyes to the mandibular insertions. Thus in full face view the anterior half of the head is distinctly narrower than the posterior half (See Plate I2, Fig. I). There are sculptural differences as well, for the female and the media lack the roughened areas on the clypeus and its surface, as well as that of the truncated parts which flank it, is granulo-shagreened only. The roughened ridges are present on the sides of the head but they are feebler than those of the major and the oval foveolae show more plainly.

A comparable condition is found in C. (Myrmaphaenus) andrei Forel, which occurs on the Mexican plateau. Moreover, the major of andre $i$ is remarkably like that of yogi, both in the anterior truncation of the head and in the structure of the clypeus. ${ }^{3}$ Since andrei has a strongly polymorphic worker caste it would appear that we are reaching some uniformity in the species assigned to Myrmaphaenus. At least we have in yogi, andrei and ulcerosus three species where

\footnotetext{
${ }^{3}$ The insect which Forel described as the major of andrei is actually a media. Neither he nor Wheeler ever saw the major of andrei, which is a very distinct caste.
} 
the worker caste is polymorphic, the front of the head of the major is truncated, the clypeus of the major is flat and ecarinate or nearly so, the anterior border of the clypeus of the major is distinctly (often deeply) impressed and the head of the female resembles that of the media. These three species form a reasonably compact geographic group, since yogi occurs in southern California, ulcerosus in western 'Texas, southern Arizona and northern Chihuahua and andrei in Durango, Zacatecas and Hidalgo. It seems best to recognize the common structural and geographical affinities of these species and we believe that Emery's assignment of yogi to the subgenus Myrmaphaenus is the correct procedure.

The meager biological data which we can present at this time are as tantalizing as the taxonomic history of yogi has been confusing. The type specimens were taken, according to Wheeler, "from a hollow twig of manzanita ... on Point Loma, near San Diego." The scnior author has examined considerable manzanita and live oak in coastal southern California without successfully relocating the species. Quite by accident the junior author was led to an examination of the living stems of Haplopappus pinifolius (Gray) Hall.

This shrub occurs in the foothill chaparral of the San Gabriel, San Bernardino and San Jacinto Mountains south to San Diego County. Although this species does not occur on Point Loma (the type locality of yogi), a related species, H. palmeri (Gray) Hall, is found there. It is possibly significant that all the records of yogi thus far are from areas where one or the other of these species of Haplopappus is known to occur.

To date, the junior author has taken six colonies of yogi, all from stems of $H$. pinifolius. The most unusual point of this association is that all six colonies were taken from living stems. Numerous dead stems were examined, but only traces of former occupancy by yogi were found in these. So far as is known the ant does no excavation of the living tissues; all galleries are merely appropriated burrowings of buprestid larvae, apparently of one or two species of Acmaeodera. 'The manner in which the founding queen initially gains entry into the beetle burrows is not known.

Attempts to discover something of the foraging activities of $y \circ g i$ have so far been futile. No foraging individuals have been seen during the day or at night. However, observations on a captive

Explanation of Plate 13

Camponotus (Myrmaphaenus) yogi Wheeler. Fig. 1. Male. Fig. 2. Minor. Fig. 3. Major. Fig. 4. Female. All figures drawn to the same scale. 

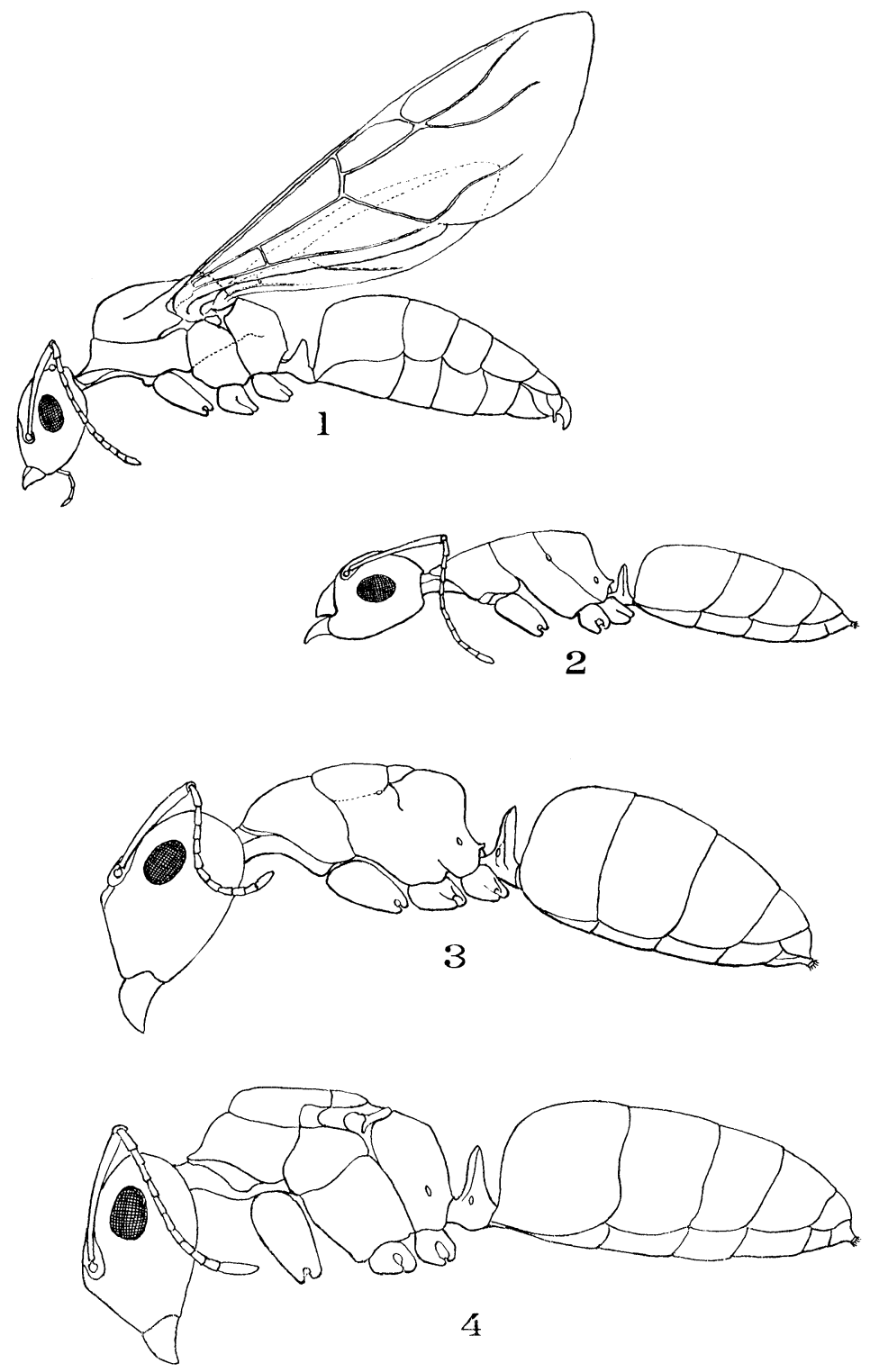

Creighton and Snelling-Camponotus 
colony suggest that this species regularly forages at night. During the day, members of the captive colony normally remained crowded within galleries cut into a wood block; with the coming of darkness they moved out of the tunnels to the surface of the block to feed on a honey-water solution provided for them.

The captive colony showed no interest in dead insects nor in various vegetable foods (seeds, bran, wheat germ, pollen, etc.). The primary food source seems to be the sweet exudates of several species of Pseudococcidae. Species of mealybugs are: Puto sp. ${ }^{4}$, (immatures only), IIumococcus inornatus $\mathrm{McKenzie}^{5}$, Anisococcus crawii (Coquillett) $^{5}$ and Chorizococcus abroniae McKenzie?5. The first two species were taken from the galleries occupied by the ant, and were feeding on the plant within these galleries. In the case of the two latter species there is some confusion, since both were mixed in a single vial; some of the specimens are known to have come from the galleries while others were taken feeding on the outer surface of the stems and crowns. Whether or not the ants actually moved the mealybugs into the gaileries remains to be determined. However, that ants do transport mealybugs to advantageous feeding sites is well known, and it would not be amiss to suggest that yogi does so.

Two ant species have been found living in a plesiobiotic relationship with yogi. There are Solenopsis (D.) molesta validiuscula Emery and Leptothorax andrei Emery. Each of these was found only once, and little can be said here regarding their relationship with yogi. The former species is commonly associated with larger ants, and the latter has been taken several times from colonies of various species of Camponotus and Formica.

One colony was apparently being attacked at the time it was collected. The attacker was Formica (F.) pilicornis Emery, a common and aggressive species in the lower chaparral region. The Formica had gained entrance into the galleries of the Camponotus, and workers of the former were seen carrying off the larvae and pupae of yogi. The remainder of the yogi colony, soldiers, workers, the queen and some brood, were crammed into three upper galleries, the majors lowest and receiving the brunt of the attack. The majors of $y$ og $i$ were massed together, with antennae extended forward; when a pilicornis worker touched the antennae the yogi major lurched forward and attempted to fasten its jaws to an appendage of the attacker. Several such encounters were noted; when the defender's

${ }^{4}$ determined by H. L. McKenzie

${ }^{5}$ determined by R. F. Wilkey 
jaws closed over the appendage of a pilicornis, the yogi major jerked back into the original position; at the same time the head was snapped up and down. This frequently resulted in severing or severely mangling the appendage of the attacker.

It was noted that the Formica so attacked usually retreated in a highly agitated manner. Closer observation of the process revealed that when the jaws of the yogi major clamped over an attacker's appendage a grayish-white exudate oozed forth from the lower part of the major's head. Creighton (5) noted a similar occurrence in the case of $C$. (Colobopsis) papago, with the remark that the fluid came from the mouth. Subsequent examination of the yogi majors suggested that in the case of this species, it is exuded from the mandibular bases; individuals which had the hardened material quite conspicuous on the mandibles and lower portions of the face showed no traces of it in the immediate vicinity of the mouthparts. This fluid, when in contact with the integument of ants of other species, causes considerable excitation of the individual affected, and, in the case of the pilicornis, an immediate retreat from the conflict. That this fluid serves as a defensive repellent seems obvious; whether or not it is toxic as well is not yet known.

The colonies of $y \circ g i$ thus far collected have been rather small; it is doubtful if colonies exceed three hundred individuals. Colony no. I, collected on May II, contained 27 majors and I65 media and minor workers; the queen was not located, but is presumed to have been overlooked during the collecting. Colony no. 4, collected on September 29, contained I queen, 8 males, 54 majors, 90 media and minor workers, 5 I larvae and 7 pupae $\left(5 \sigma^{\top} \sigma^{\top}, 2\right.$ 우); colony no. 5, also taken on September 29, consisted of I queen, I alate female, 3 males, I 2 majors and 36 media and minor workers, and is the smallest colony taken to date.

The mating flight evidently takes place during late summer. Winged sexuals have been taken in the nests in late August and September; winged females have been attracted to lights at night in Glendale, Los Angeles County, on October I 4 .

\section{Literature Cited}

1. Wheeler, W. M., Bull. Amer. Mus. Nat. Hist., 34: 420 (1915)

2. Creighton, W. S., Bull. Mus. Comp. Zoöl., 104: 401 (1950)

3. Emery, Carlo, Mem. Acad. Sci. Bologna, 5: 761-780 (1896)

4. Wheeler, W. M., Bull. Amer. Mus. Nat. Hist., 20: 140 (1904)

5. Creighton, W. S., Psyche, 59, 4: 161 (1952) 

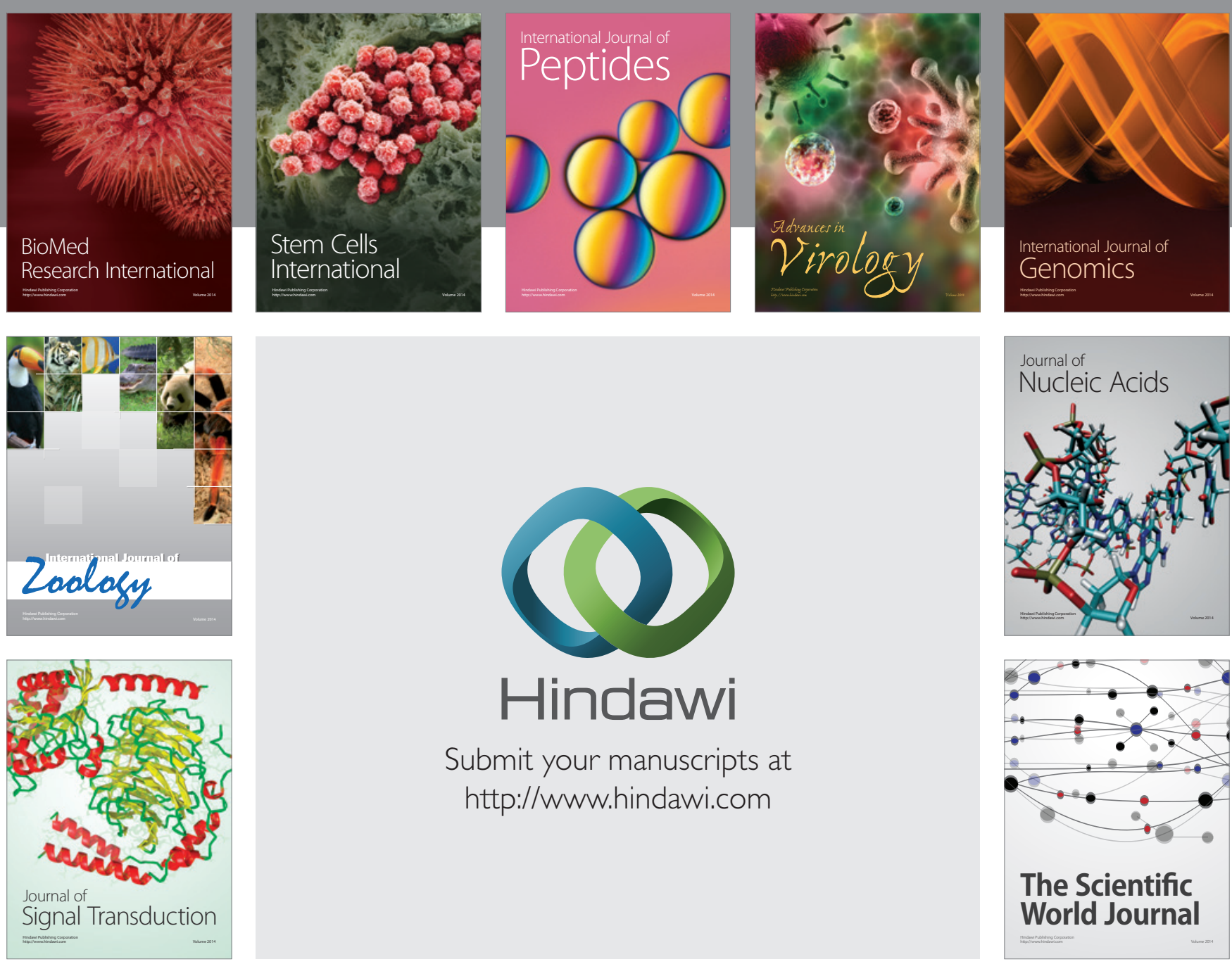

Submit your manuscripts at

http://www.hindawi.com
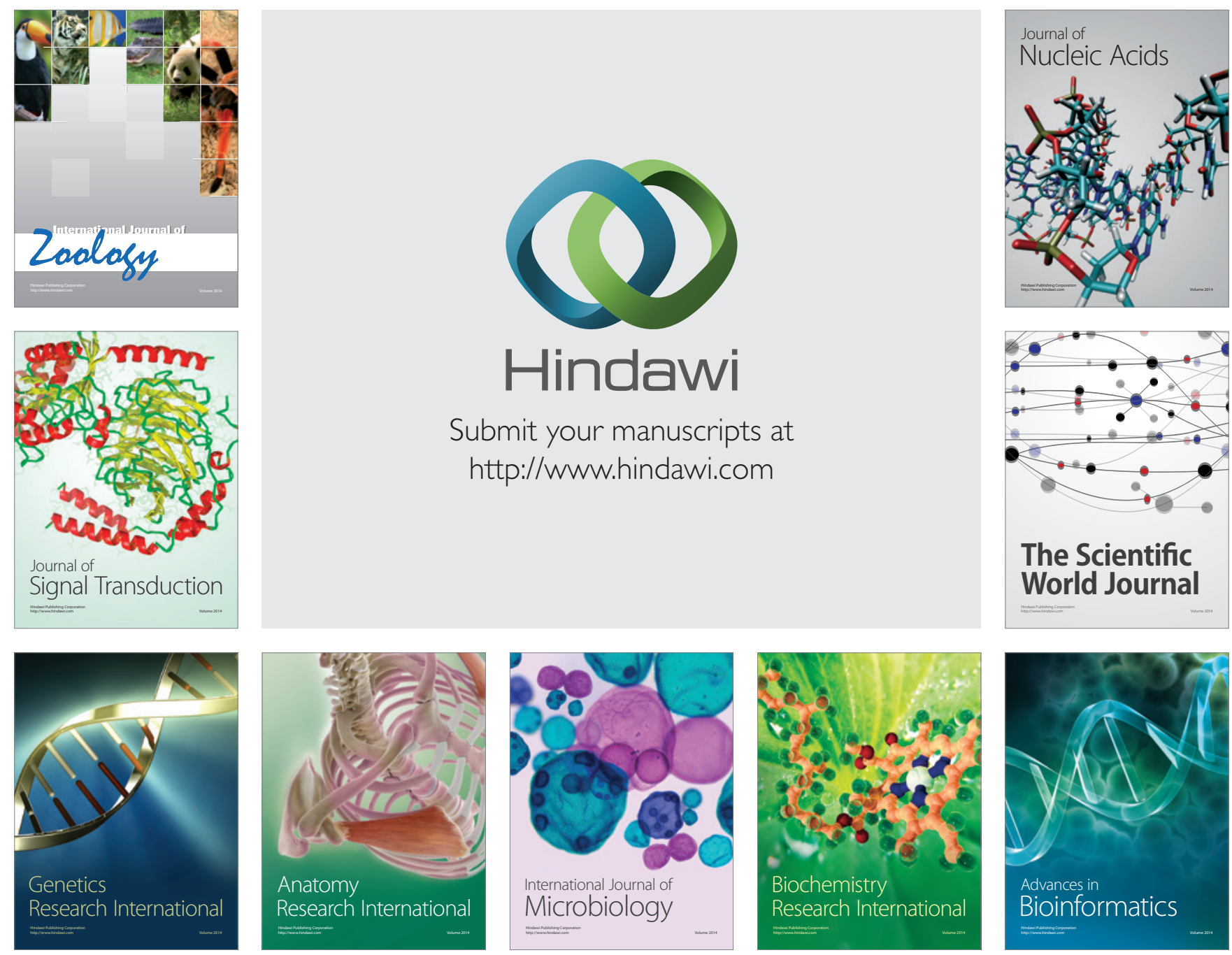

The Scientific World Journal
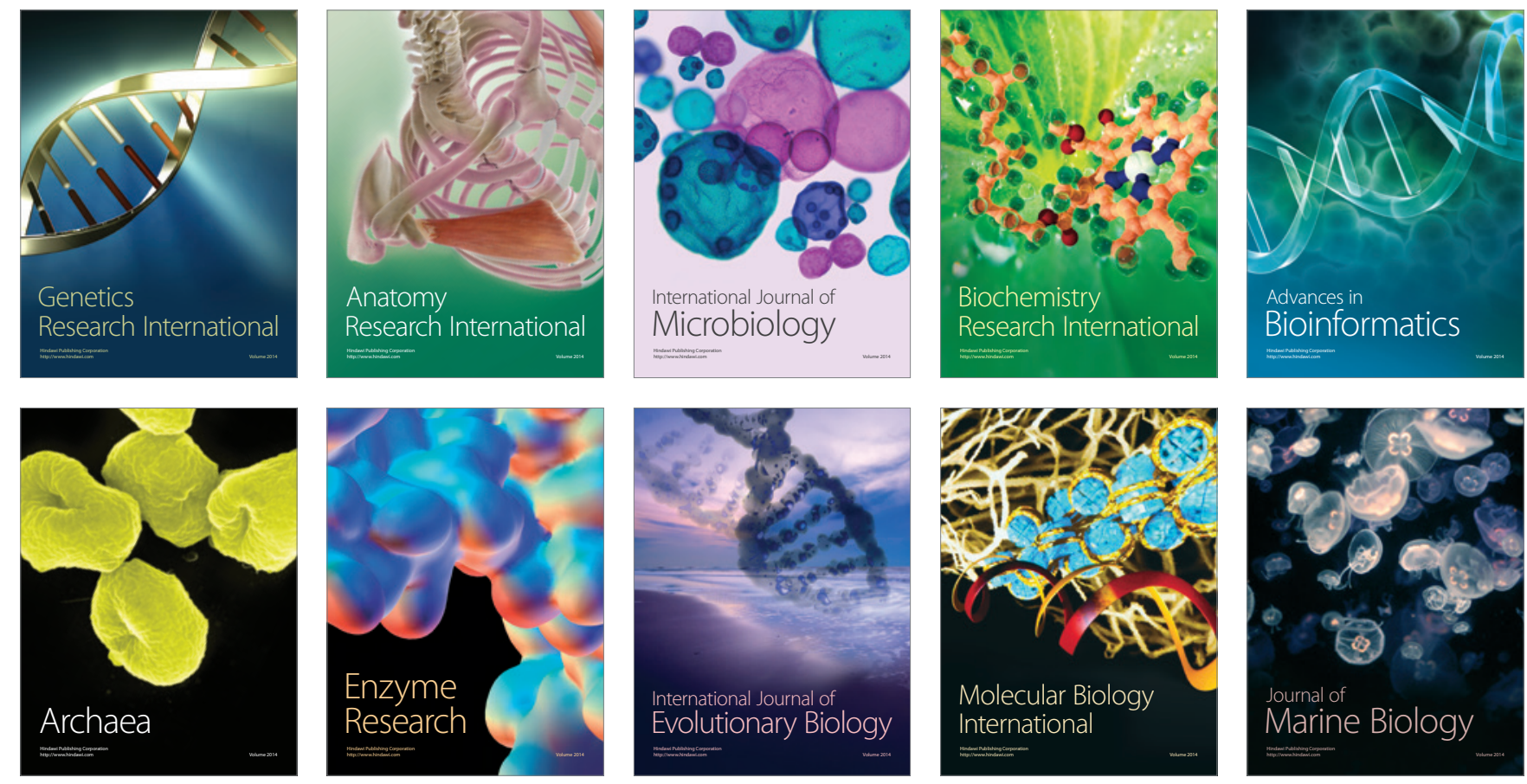